\title{
The Deployment of Conditional Probability Distributions for Death Time Estimation
}

\author{
F. M. Biermann ${ }^{a}$ S. Potente ${ }^{b}$ \\ ${ }^{a}$ The Hebrew University of Jerusalem, Department of Economics, Mount Scopus Campus, Jerusalem 91905, Israel \\ ${ }^{\mathrm{b}}$ J.W.-Goethe-University, Department of Legal Medicine, Kennedyallee 104, 60596 Frankfurt am Main, Germany
}

\begin{abstract}
The temperature based algorithm known as the Nomogram Method for the determination of a 95.45\% death-time interval can be combined with non-temperature based (NTB) findings in the so called Compound Method (CM). The impact of such integration on the probability yielded by the resulting interval has however neither been described nor exploited. In fact the interval after integration of NTB findings rarely yields $95.45 \%$ probability. We present a technique, based on the conditional probability distribution that can be calculated if the NTB findings are taken into account, which ensures the probability inside the interval to be $95.45 \%$. The technique was successfully applied to a set of 53 cases published by Henssge et al. [1] and led to a reduction of the interval width up to more than $15 \%$ compared to the CM interval, whereas in other cases the interval width increased due to probability content of the CM intervals below $95.45 \%$. A spreadsheet file in which the method proposed in this paper is implemented can be obtained upon email request from the author S. Potente.
\end{abstract}

Key words: Death Time, Nomogram Method, Compound Method

\section{Introduction}

Postmortem cooling of the body as a phenomenon of death has been known for a long time [2, 3]. Making use of Newton's Cooling Law, Marshall and Hoare derive their estimation for the time of death from the difference between the body temperature and the ambient temperature at the time of measurement $[4,5,6]$. Nonsurprisingly, in any real-life case exist many factors besides time since death which also influence this temperature difference. Therefore their formula in practice never provides the exact time of death. But nevertheless, despite of the fact that the probability distribution of the random variable "time of death" is unknown, a stochastical answer to the question of death time can be given. This is achieved through the Central Limit Theorem, according to which the true probability distribution of death time should come close to a Gauss distribution. ${ }^{1}$

Email addresses: florianb@mscc.huji.ac.il (F. M. Biermann), s.potente@em.uni-frankfurt.de (S. Potente).

1 The central limit theorem claims that the distribution of a sum of $n$ random variables under relatively general conditions asymptotically approaches a Gauss distribution (see [7], p. 186 and p. 197).
A Gauss distribution is specified up to the two parameters expected value and standard deviation. The formula of [4] provides an estimator for the expected value, while the standard deviation was estimated by Henssge $[8,9,10,11,12,13]$. There are also several corrective factors provided for adjustment if special conditions prevail. Moreover, the method has been refined for specific situations and conditions $[14,15,16,17,18]$. There also exists a variant of the method for brain temperature vs. ambient temperature $[19,20]$. There have however been some concerns regarding the methodology of body cooling based death time estimation $[21,22]$.

The Nomogram Method (NM) [8] operates under the assumption that the whole of $100 \%$ probability is spread out over eternity. In other words: only under the condition that death can have occurred at any point in time (even the future!), the area yielding $95.45 \%^{2}$ of the probability

2 For Gauss distributions, a probability of almost exactly $95.45 \%$ is contained in a four-standard-deviation interval centered around the expected value. The inverval borders of NM take this form and thus contain $95.45 \%$. (Nevertheless the authors in [8] repeatedly approximate this probability as $95 \%$ ). To make our method comparable to NM, we have to construct a $95.45 \%$-interval, although with computers it is easy to construct intervals containing any probability, so the 
is correctly expressed by the death time interval. Thus, any information, non-temperature based (NTB) data or factual evidence, that rules out any time as a possible time of death, will change the probability distribution and thus the width and/or the position of the correct $95.45 \%$ interval.

The Compound Method (CM) [23, 1] in its most common form integrates NTB data with the NM approach by removing those times from the death time interval which have positive probability according to NM but conflict with NTB findings. By discarding the conflicting parts from the interval a narrowing is achieved compared to the solely temperature-based estimation, while in case the NTB findings do not conflict with the original interval, they are ignored. So the CM scope is limited to the $95.45 \%$ NM interval and dismissals of death times outside the interval borders have no impact on the procedure's result. When NTB data suggests a dismissal in close proximation of the interval's borders, the authors of [1] acknowledge this as a "confirmation" of the interval's borders. Finally the resulting, possibly narrowed interval is given as the new valid interval. The compound method has been documented extensively [24, 25, 11, 1, 23, 26, 27].

This procedure however does not take into account the effects of dismissals of death times on the probability density within the resulting interval - which in general no longer accumulates to $95.45 \%$. Furthermore, NTB data that will not lead to any dismissal inside the NM interval's borders can in fact still contribute valid information, but it is ignored. ${ }^{3}$

In this paper we propose to resolve those problems by first deriving a probability distribution conditional on the NTB data and then computing an appropriate confidence interval for the new distribution. Contrary to CM, the interval after deployment of CPD will yield $95.45 \%$ probability in all cases.

\section{Effects of NTB findings and police evidence on the probability distribution}

We identify the time line with $\mathbb{R}$. The nature of the subject makes it possible to translate NTB findings and police evidence always into a time interval $(-\infty, \alpha]$ at which death had not yet occured, or into a time interval $[\beta, \infty)$ at which the person was already dead.

$T$ is the continuous random variable "time of death" supported on $\mathbb{R}$ (in the unconditional case) or on a subset of $\mathbb{R}$ (under the condition that some death times cannot have occured), and by $t$ we denote a realization of $T$. Let $f(t)$ be

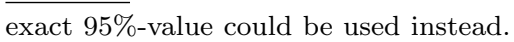

3 Factual evidence that might contribute further information is also not taken into account in CM. Such evidence might be the time when the body was found dead or times when he was proven alive the last time.
T's prior probability density function (before the NTB information was taken into account) and $\hat{f}(t)$ be the posterior probability density function (after the NTB information was considered). We denote by $N D$ those time intervals in which death has not occured according to NTB information. We set the time at which the body was found to 0 . If NTB findings indicate $\alpha$ to be the latest point of time at which the dead person was alive, and they suggest $\beta$ to be the earliest point of time at which the person was dead $(\beta>$ 0 is impossible accordingly), then $N D:=(-\infty, \alpha] \cup[\beta, \infty)$. By $P(N D)$ we denote the probability which according to $f(t)$ is assigned to $N D$, formally

$$
P(N D):=\int_{-\infty}^{\alpha} f(t) d t+\int_{\beta}^{\infty} f(t) d t
$$

If there is no reason to believe that the relative probabilities in the set $\mathbb{R} \backslash N D$ are affected by the fact that the event $N D$ has not occured, for any two nonempty intervals $^{4}[c, d],[e, f] \subseteq \mathbb{R} \backslash N D$ must hold

$$
\frac{\int_{c}^{d} f(t) d t}{\int_{e}^{f} f(t) d t}=\frac{\int_{c}^{d} \hat{f}(t) d t}{\int_{e}^{f} \hat{f}(t) d t} .
$$

Obeying the restriction

$$
\int_{-\infty}^{\infty} \hat{f}(t) d t=1
$$

the unique continuous probability density function $\hat{f}(t)$ which assigns probability 0 to $N D$ and which fulfills (1) and (2) is

$$
\hat{f}(t)= \begin{cases}\frac{f(t)}{1-P(N D)} & \text { if } t \notin N D \\ 0 & \text { if } t \in N D .\end{cases}
$$

This fact is proved in the appendix. Such conditional density function of a univariate random variable is ubiquitously used in applied statistics but, to our knowledge, has not yet found its way into death time estimation.

For those who do not want to follow the proof in the appendix we present an intuition which is based on a purely frequentist interpretation of probabilities. ${ }^{5}$ Assume there are $N$ bodies with the same difference between body temperature and ambient temperature. If the death times of these $N$ bodies are drawn from a random variable with continuous density function $f(t)$, then one would expect that in a certain time interval $I=[a, b]$, which carries probability $P(I)=\int_{a}^{b} f(t) d t, P(I) \cdot N$ of the persons have died. In the same way, one would expect $P(B) \cdot N$ of the $N$ cases to have died in $B$ for an interval $B$ with $I \subseteq B$. Hence, of these $P(B) \cdot N$ cases, a fraction of $\frac{P(I) \cdot N}{P(B) \cdot N}$ would

\footnotetext{
4 To be precise, the intervals $[c, d]$ and $[e, f]$ must yield probability greater than 0 according to the probability density functions $f(t)$ and $\hat{f}(t)$.

5 This intuition was communicated to us by professor Anton Bovier, University of Bonn.
} 
be expected to have died in $I$. Let $B$ be the interval which is left after the integration of NTB data. Then all $N$ bodies must have died within $B$, and thus the probability of a given person to have a death time within $I$ is $\frac{P(I) \cdot N}{P(B) \cdot N}=$ $\frac{P(I)}{P(B)}$, which complies with the density function (3).

To illustrate the problem of CM, we discuss the case that $N D$ is an interval $(-\infty, \alpha]$. The NM confidence interval is denoted by $[b, c]$ with $b \leq \alpha \leq c$ and for simplicity we assume it contains a probability of exactly 0.95 (instead of 0.9545). Then the new interval reported according to $\mathrm{CM}$ is $[\alpha, c]$. Denote the probability which the conditional probability density function $\hat{f}(t)$ assigns to $[\alpha, c]$ by $P([\alpha, c])$. Using (3), for $b \leq \alpha \leq c$ we can express this probability as a function of $\alpha$ by

$$
P([\alpha, c])(\alpha)=\frac{\int_{\alpha}^{c} f(t) d t}{1-\int_{-\infty}^{\alpha} f(t) d t} .
$$

Setting $P([\alpha, c])(\alpha)=0.95$, after some tranformations we obtain

$$
\int_{b}^{\alpha} f(t) d t=0.475 .
$$

Hence, only if $\alpha$ fulfills equation (4), the interval computed with CM contains $95 \%$ probability. ${ }^{6}$

\section{An alternative way to compute the confidence interval}

As was explained above, probability distributions can be transformed into conditional probability distributions when the conditions are known. When the (conditional) probability distribution is known, intervals for any probability mass in question can be determined and vice versa. The goal of our method, the conditional probability distribution (CPD) method, is set to result in a reliable $95.45 \%$ interval to be used both in practical casework and in court.

To facilitate this procedure, it was shown how the new probability distribution, which is conditional on the NTB data, can be generated. The next step is to choose one of the usually infinitely many intervals of the conditional probability density function which contain a probability of $95.45 \%$. We will explain the way which in our opinion is the most straightforward to do this.

Given the conditional probability density function $\hat{f}(t)$ which was specified in expression (3), define

$$
\begin{array}{r}
I_{\hat{f}(t)}:=\quad\{[a, b] \mid \hat{f}(t) \text { is continuous on }[a, b], \\
\left.\int_{a}^{b} \hat{f}(t) d t=0.9545\right\}
\end{array}
$$

\footnotetext{
$\overline{6}$ If $f(t)$ is the Gaussian probability density function, equation (4) cannot be solved for $\alpha$ in a closed form (see [7], p. 189). But because $0.475=\frac{0.95}{2}$, we know that (4) is solved by $\alpha=\mu$, with $\mu$ being the expected value of the Gaussian distribution.
}

to be the set of all intervals on which $\hat{f}(t)$ is continuous and which contain probability of 0.9545 . Usually the forensic expert wants to report an interval which is as narrow as possible, so that we define an optimal 0.9545-confidence interval for the function $\hat{f}(t)$ to be an interval $[a, b]$ which fulfills two properties:

(i) $[a, b] \in I_{\hat{f}(t)}$

(ii) $|a-b| \leq|c-d| \quad \forall \quad[c, d] \in I_{\hat{f}(t)}$.

If $f(t)$ is the Gaussian density function, then $\hat{f}(t)$ has a unique optimal confidence interval.

To sum up, instead of using the CM procedure, we propose to compute an optimal 0.9545-confidence interval for the probability density function (3) which is conditional on the NTB data. In practice, this can be done by an algorithm which is so frugal that it can be implemented for real death time estimation with a software as simple as Microsoft $\left.{ }^{(}\right)$ Excel ${ }^{\circledR}$. The spreadsheet file in which this is done can be obtained on email request from the author S. Potente, accompanied by a manual which contains a detailed exposition of the algorithm.

\section{Practical application of the CPD method}

For demonstration and as a proof-of-concept, the CPD method was applied to a set of external data. Henssge et al. [1] applied CM to 72 crime scene cases in a field study. For 53 of these cases the CM data was given in detail with one case tested twice over time (leading to a total of 54). The CPD method was applied to all 53 cases. The results are given in the table in appendix $\mathrm{B}$.

We start with an example which illustrates how to read the table. In the following exposition, "lower limit" of a death time interval denotes the boundary closer in time to the finding of the body, while "upper limit" refers to the boundary further remote in the past. Consider case No. 12: Application of NM led to an expected value of -6.9 hours prior to measurement. The interval width was 5.6 hours (+/-2.8 h, corresponding to a variance of 1.96). Electric excitability of fascial muscles grade II was present when CM was applied, so the lower limit of the CM interval given was -5 hours. For the upper limit no findings "better" than the NM boundary were found, so the NM interval upper limit was taken as CM interval upper limit accordingly, resulting in a CM interval from $-5 \mathrm{~h}$ to $-9.7 \mathrm{~h}$ (interval width $4.7 \mathrm{~h}$ ). For the CPD algorithm the same lower limit was taken for the lower limit of possible death time. No information was given as to when the person was last seen alive, so the upper limit was set to -10.000 . Had there been any information available such as that it was certain that the person was alive 12,15 or even 30 hours ago this information would have entered accordingly and the result would have further improved. The given information was processed through the CPD algorithm with an 
Excel $^{\circledR}$ datasheet which can be obtained by email from S. Potente. The resulting CPD 95.45\%-interval limits are -5 h to -9.3 prior to measurement (CPD interval width 4.3 hours ). The CPD interval is 0.37 hours shorter than the CM interval (approximately $7.95 \%$ improvement).

In the original paper [1] the CM led to a narrowing of the death-time interval as determined via Henssge's NM in 48 out of 53 cases with width improvements between $-1.5 \%$ and $-92.86 \%$. In the case of $92.86 \%$ narrowing, the remaining death time interval held only $47.38 \%$ probability (case 48, where in Henssge et al. [1] application of CM was rejected for reasons of an unusually large dismissal). In 6 cases out of 53 the CM did not achieve an improvement of the interval width as compared to NM even though the borders were "confirmed", which means that the CM interval boundaries were close to the NM boundaries.

The CPD algorithm achieved a narrowing of the death time interval compared to the CM-interval in 43 out of 53 cases. The range of improvement was between $-0.01 \%$ and $-15.21 \%$ (between $0 \%$ and $5 \%$ in 9 cases, between $5 \%$ and $10 \%$ in 24 cases, and more than $10 \%$ in 10 cases). The six cases with no narrowing achieved by CM were all narrowed using CPD (between $-1.75 \%$ and $-8.52 \%$ ). In 9 cases the dismissal in CM was so large that the probability in the given CM interval was less than $95.45 \%$ (between $47.38 \%$ and $94.87 \%$ ). The true $95.45 \%$-interval for these cases calculated using CPD was therefore wider compared to the CM interval (between $+2.71 \%$ and $+309.17 \%$ ). However, in those cases the resulting CPD intervals were all smaller than the original NM-interval (between $-51.79 \%$ and $-71.43 \%$ ). It should be noted that in 9 cases no information was provided about the time the person was found dead or was last seen alive respectively. In retrospect this information could have been obtained easily at the scene and might have led to further improvements when using CPD.

\section{Conclusions and Outlook}

The CM approach is a reasonable and useful add-on to conventional death time estimation based on body cooling such as NM. ${ }^{7}$ However, the application of CM will alter the probability distribution of the random variable "time of death", and the resulting intervals will rarely hold 95.45\% probability (this happened in only two out of 53 cases which are displayed in the table in appendix B). The CPD method, on the other hand, will always lead to a correct $95.45 \%$ interval for use both in court and investigations. This interval will always be smaller than the initial interval determined by the NM algorithm and in some

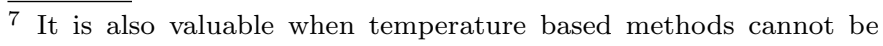
used for one reason or another, even though this aspect is not subject of this paper.
}

cases smaller than the interval after application of CM.

The application of the algorithm to case data of 53 forensic cases (published in Henssge et al. [1]) illustrate both the need for and the potential of CPD application in death time estimation. Every reader is invited to request by email the Excel $^{\circledR}$ file for testing, which comes bundled with a thorough explanation of the mathematical procedures used.

\section{Acknowledgements}

Florian Biermann is grateful for financial support by Minerva Foundation, Germany. Contents of this paper have been presented by Stefan Potente at the annual meeting of the German Association of Legal Medicine (DGRM) in Dresden, September 24th, 2008. The authors are indebted to professor Anton Bovier, University of Bonn, for proofreading the mathematical part of the paper and giving some helpful comments, and to Jan Klingelhöfer, Institute for International Economic Studies (Stockholm), for some ideas how to present the content of section 2 .

\section{References}

[1] C. Henssge, L. Althaus, J. Bolt, Freislederer, H.T. Haffner, C. Henssge, B. Hoppe, V. Schneider, Experiences with a Compound Method of Estimating the Time since Death. II. Integration of nontemperature-based Methods, International Journal of Legal Medicine 113 (2000) 320-331.

[2] B. Madea, C. Henssge, Historisches zur Todeszeitbestimmung, Zeitschrift für Rechtsmedizin 95 (1985) 1925.

[3] B. Knight, The evolution of methods for estimating the time of death from body temperature, Forensic Science International 36 (1988) 47-55.

[4] T. Marshall, F. Hoare, Estimating the time of death. The rectal cooling after death and its mathematical expression, Journal of Forensic Science 7 (1962) 56-81.

[5] T. Marshall, F. Hoare, Estimating the Time of Death. The Use of the Cooling Formula in the Study of Postmortem Body Cooling, Journal of Forensic Science 7 (1962) 189-210.

[6] T. Marshall, F. Hoare, Estimating the Time of Death. The Use of Body Temperature in Estimating the Time of Death., Journal of Forensic Science 7 (1962) 211221.

[7] G. Schay, Introduction to Probability with Statistical Applications, Birkhäuser, 2007.

[8] C. Henssge, Death Time Estimation in Case Work. I. The Rectal Temperature Time of Death Nomogram., Forensic Science International 38 (1988) 209-236.

[9] C. Henssge, L. Althaus, A. Freislederer, H.-T. Haffner, C. Henssge, B. Hoppe, V. Schneider, Experiences with a compound method for estimating the time since death. I. Rectal temperature nomogram for time since 
death, International Journal of Legal Medicine 113 (2000) 303-319.

[10] C. Henssge, Todeszeitschätzung durch die mathematische Beschreibung der rektalen Leichanbkühlung unter verschiedenen Abkühlungsbedingungen, Zeitschrift für Rechtsmedizin 87 (1981) 147-178.

[11] C. Henssge, B. Madea, Methoden zur Bestimmung der Todeszeit an Leichen, Verlag Schmidt Römhild, 1988.

[12] A. Albrecht, I. Gerling, C. Henssge, M. Hochmeister, M. Kleiber, B. Madea, M. Oehmichen, S. Pollak, K. Püschel, D. Seifert, K. Teige, Zur Anwendung des Rektaltemperatur-Todeszeit-Nomogramms am Leichenfundort, Zeitschrift für Rechtsmedizin 103 (1990) 257-278.

[13] C. Henssge, B. Knight, The Estimation of Time since Death in the early Postmortem Interval, Oxford University Press, 1998.

[14] L. Althaus, C. Henssge, Rectal temperature time of death nomogram: sudden change of ambient temperature, Forensic Science International 99 (1999) 171178.

[15] L. Althaus, S. Stückradt, C. Henssge, T. Bajanowski, Cooling experiments using dummies covered by leaves, International Journal of Legal Medicine 121 (2007) $112-114$.

[16] C. Henssge, B. Brinkmann, K. Püschel, Todeszeitbestimmung durch Messung der Rektaltemperatur bei Wassersuspension der Leiche, Zeitschrift für Rechtsmedizin 92 (1984) 255-276.

[17] P. Karhunen, S. Goebeler, O. Winberg, M. Tuominen, Time of death of victims found in cold water environment, Forensic Science International 176 (2008) 2-3.

[18] C. Henssge, Rectal temperature time of death nomogram: dependendce of corrective factors on the body weight under stronger thermic insulation conditions, Forensic Science International 54 (1992) 51-66.

[19] C. Henssge, E.-R. Beckmann, F. Wischhusen, B. Brinkmann, Todeszeitbestimmung durch Messung der zentralen Hirntemperatur, Zeitschrift für Rechtsmedizin 93 (1984) 1-22.

[20] C. Henssge, R. Frekers, Reinhardt, E.-R. Beckmann, Todeszeit auf Basis simultaner Messung von Hirn- und Rektaltemperatur, Zeitschrift für Rechtsmedizin 93 (1984) 123-133.

[21] N. Demierre, D. Wyler, U. Zollinger, S. Bollinger, T. Plattner, Elevated Body Core Temperature in Medico-Legal Investigation of Violent Death, American Journal of Forensic Medicine and Pathology 30 (2009) 155-158.

[22] Y. Kanawaku, J. Kanetake, A. Komiya, S. Maruyama, M. Funayama, Effects of rounding errors on postmortem temperature measurments caused by thermometer resolution, International Journal of Legal Medicine 121 (2007) 267-273.

[23] C. Henssge, B. Madea, E. Gallenkemper, Death Time Estimation in Case Work. II. Integration of Different Methods, Forensic Science International 39 (1988) 77-
87.

[24] C. Henssge, B. Knight, T. Krompecher, B. Madea, L. Nokes, The Estimation of Time since Death in the Early Postmortem Period, Arnold, 2nd edition, 2002.

[25] B. Madea, Praxis Rechtsmedizin, Springer-Verlag, 2003.

[26] C. Henssge, B. Madea, E. Gallenkemper, Todeszeitbestimmung - Integration verschiedener Teilmethoden, Zeitschrift für Rechtsmedizin 95 (1985) 185-196.

[27] C. Henssge, B. Madea, Estimation of the time since death in the early post-mortem period, Forensic Science International 144 (2004) 167-175.

\section{Appendices}

\section{Appendix A. Proof of the statement made in section 2}

Proposition $\hat{f}(t)$, the probability density function (3) on page 2, is the only continuous function which assigns probability of 0 to ND and fulfills conditions (1) and (2) of the same page.

Proof. Let $\bar{f}(t) \neq \hat{f}(t)$ be another such function which fulfills (1) and (2). It will be shown that this leads to a contradiction. Without loss of generality assume $\bar{f}(x)>\hat{f}(x)$ at some point $x \in \mathbb{R} \backslash N D$. It is clear from continuity of both functions that then there exists an interval $[a, b] \subseteq \mathbb{R} \backslash N D$ which has measure greater zero, $x \in[a, b]$, and $\bar{f}(y)>\hat{f}(y)$ for all $y \in[a, b]$. So clearly it holds

$$
\int_{a}^{b} \bar{f}(t) d t>\int_{a}^{b} \hat{f}(t) d t
$$

and hence condition (2) ensures the existence of another inteval $[c, d] \subseteq \mathbb{R} \backslash N D$ with

$$
\int_{c}^{d} \bar{f}(t) d t<\int_{c}^{d} \hat{f}(t) d t .
$$

Therefore

$$
\frac{\int_{a}^{b} \hat{f}(t) d t}{\int_{c}^{d} \hat{f}(t) d t}<\frac{\int_{a}^{b} \bar{f}(t) d t}{\int_{c}^{d} \bar{f}(t) d t}
$$

obviously contradicting the requirement (1), which is

$$
\frac{\int_{a}^{b} \hat{f}(t) d t}{\int_{c}^{d} \hat{f}(t) d t}=\frac{\int_{a}^{b} f(t) d t}{\int_{c}^{d} f(t) d t}=\frac{\int_{a}^{b} \bar{f}(t) d t}{\int_{c}^{d} \bar{f}(t) d t} .
$$


Appendix B. Application of the CPD method to the 53 cases of Henssge et al. [1]

\begin{tabular}{|c|c|c|c|c|c|c|c|c|c|c|c|c|c|}
\hline $\begin{array}{l}\text { CASE } \\
\text { No. }\end{array}$ & $\begin{array}{c}\mathrm{NM}- \\
\text { exp. } \\
\text { Value } \\
\mathrm{h}\end{array}$ & $\begin{array}{c}\mathrm{NM} \\
\text { bounds }\end{array}$ & $\begin{array}{l}\mathrm{CM}- \\
\text { lower } \\
\text { bound } / \mathrm{h}\end{array}$ & $\begin{array}{c}\text { CM - } \\
\text { upper } \\
\text { bound/h }\end{array}$ & $\begin{array}{l}\mathrm{CM} \text { - } \\
\text { interval } \\
\text { width } / \mathrm{h}\end{array}$ & $\begin{array}{c}\mathrm{CM}- \\
\text { interval } \\
\text { probability }\end{array}$ & $\begin{array}{c}\text { Possible } \\
\text { death } \\
\text { time } \\
\text { interval - } \\
\text { lower } \\
\text { bound } / \mathrm{h} \\
\left({ }^{*}\right)\end{array}$ & $\begin{array}{c}\text { Possible } \\
\text { death } \\
\text { time } \\
\text { interval - } \\
\text { upper } \\
\text { bound/h } \\
(+)\end{array}$ & $\begin{array}{c}\text { CPD - } \\
\text { lower } \\
\text { bound } / \mathrm{h}\end{array}$ & $\begin{array}{l}\text { CPD - } \\
\text { upper } \\
\text { bound } \\
\text { /h }\end{array}$ & $\begin{array}{l}\text { CPD - } \\
\text { interval } \\
\text { width } \\
\text { /h }\end{array}$ & $\begin{array}{l}\text { CPD vs. } \\
\text { CM - } \\
\text { width } \\
\text { change, } \\
\text { absolute } \\
\text { /h }\end{array}$ & $\begin{array}{l}\text { CPD vs. } \\
\text { CM- } \\
\text { width } \\
\text { change, } \\
\text { Percent }\end{array}$ \\
\hline 1 & -3.4 & $+/-2.8$ & -1.0 & -6.2 & 5.2 & $98.14 \%$ & -1.0 & -7.0 & -1.0 & -5.8 & 4.7 & -0.48 & $-9.16 \%$ \\
\hline 2 & -2.7 & $+/-2.7$ & -1.0 & -5.4 & 4.4 & $98.26 \%$ & -1.0 & -6.0 & -1.0 & -5.0 & 4.0 & -0.45 & $-10.20 \%$ \\
\hline 3 & \begin{tabular}{|l|}
-8.2 \\
\end{tabular} & $+/-2.8$ & -5.4 & -11.0 & 5.6 & $97.68 \%$ & -3.0 & -11.0 & -5.6 & -10.8 & 5.1 & -0.48 & $-8.52 \%$ \\
\hline 4 & -4.8 & $+/-2.8$ & -5.0 & -7.6 & 2.6 & $94.87 \%$ & -5.0 & -10000 & -5.0 & -7.7 & 2.7 & 0.07 & $2.71 \%$ \\
\hline 5 & -3.6 & $+/-2.8$ & -1.0 & -6.0 & 5.0 & $100.00 \%$ & -1.0 & -6.0 & -1.4 & -5.8 & 4.4 & -0.61 & $-12.21 \%$ \\
\hline 6 & -4.8 & $+/-2.8$ & -3.0 & -7.6 & 4.6 & $98.69 \%$ & -3.0 & -8.0 & -3.0 & -7.1 & 4.1 & -0.52 & $-11.28 \%$ \\
\hline 7 & -5.8 & $+/-2.8$ & -3.0 & -8.0 & 5.0 & $100.00 \%$ & -3.0 & -8.0 & -3.6 & -8.0 & 4.3 & -0.68 & $-13.54 \%$ \\
\hline 11 & -21.2 & $+/-4.5$ & -16.7 & -22.0 & 5.3 & $96.44 \%$ & 0.0 & -22.0 & -16.9 & -22.0 & 5.1 & -0.24 & $-4.47 \%$ \\
\hline 12 & \begin{tabular}{|l|}
-6.9 \\
\end{tabular} & $+/-2.8$ & -5.0 & -9.7 & 4.7 & $97.51 \%$ & -5.0 & -10000 & -5.0 & -9.3 & 4.3 & -0.37 & $-7.95 \%$ \\
\hline 15 & -3.1 & $+/-2.8$ & -3.0 & -5.9 & 2.9 & $99.30 \%$ & -3.0 & -6.0 & -3.0 & -5.5 & 2.5 & -0.39 & $-13.31 \%$ \\
\hline 17 & -22.1 & $+/-7$ & -15.1 & -29.1 & 14.0 & $96.45 \%$ & -14.0 & -10000 & -15.4 & -28.8 & 13.4 & -0.59 & $-4.20 \%$ \\
\hline 18 & -19.6 & $+/-4.5$ & -15.1 & -24.1 & 9.0 & $96.07 \%$ & -14.0 & -10000 & -15.2 & -24.0 & 8.8 & -0.24 & $-2.68 \%$ \\
\hline 19 & \begin{tabular}{|l|}
-8.8 \\
\end{tabular} & $+/-2.8$ & -6.0 & -10.0 & 4.0 & $97.17 \%$ & -3.0 & -10.0 & -6.3 & -10.0 & 3.7 & -0.29 & $-7.30 \%$ \\
\hline 20 & \begin{tabular}{|l|}
-8.4 \\
\end{tabular} & $+/-2.8$ & -5.6 & -8.0 & 2.4 & $94.19 \%$ & -3.5 & -8.0 & -5.5 & -8.0 & 2.5 & 0.14 & $5.85 \%$ \\
\hline 21 & -24 & $+/-5.9$ & -18.1 & -24.0 & 5.9 & $95.45 \%$ & -5.0 & -24.0 & -18.1 & -24.0 & 5.9 & 0.00 & $0.00 \%$ \\
\hline 22 & -2.45 & $+1-2.45$ & -1.0 & -4.9 & 3.9 & $97.43 \%$ & -1.0 & -7.0 & -1.0 & -4.6 & 3.6 & -0.31 & $-7.91 \%$ \\
\hline 23 & \begin{tabular}{|l|}
-8.9 \\
\end{tabular} & $+/-2.8$ & -6.1 & -8.0 & 1.9 & $91.26 \%$ & -3.0 & -8.0 & -5.7 & -8.0 & 2.3 & 0.37 & $19.30 \%$ \\
\hline 24 & -6.5 & $+/-2.8$ & -3.7 & -9.3 & 5.6 & $97.62 \%$ & -3.5 & -10.0 & -3.9 & -9.1 & 5.1 & -0.47 & $-8.34 \%$ \\
\hline 26 & -9.1 & $+/-2.8$ & -6.3 & -8.0 & 1.7 & $89.47 \%$ & -2.0 & -8.0 & -5.8 & -8.0 & 2.2 & 0.47 & $27.41 \%$ \\
\hline 27 & -5.6 & $+/-2.8$ & -5.0 & -8.4 & 3.4 & $96.58 \%$ & -5.0 & -10000 & -5.0 & -8.2 & 3.2 & -0.17 & $-5.09 \%$ \\
\hline 28 & -6.3 & $+/-2.8$ & -5.0 & -8.0 & 3.0 & $100.00 \%$ & -5.0 & -8.0 & -5.0 & -7.8 & 2.8 & -0.22 & $-7.22 \%$ \\
\hline 31 & -4.2 & $+/-2.8$ & -3.0 & -7.0 & 4.0 & $97.57 \%$ & -3.0 & -8.0 & -3.0 & -6.7 & 3.7 & -0.35 & $-8.63 \%$ \\
\hline 33 & \begin{tabular}{|l|}
-7.5 \\
\end{tabular} & $+/-2.8$ & -5.0 & -10.3 & 5.3 & $97.64 \%$ & -5.0 & -10000 & -5.1 & -9.9 & 4.9 & -0.41 & $-7.78 \%$ \\
\hline 34 & -6.1 & $+/-2.8$ & -3.3 & -6.0 & 2.7 & $95.52 \%$ & -2.0 & -6.0 & -3.3 & -6.0 & 2.7 & -0.01 & $-0.31 \%$ \\
\hline 35 & \begin{tabular}{|l|}
-5.9 \\
\end{tabular} & $+/-2.8$ & -3.1 & -6.0 & 2.9 & $95.71 \%$ & -0.5 & -6.0 & -3.1 & -6.0 & 2.9 & -0.03 & $-1.18 \%$ \\
\hline 36 & -5.8 & $+/-2.8$ & -3.0 & -8.6 & 5.6 & $97.67 \%$ & -3.0 & -13.0 & -3.2 & -8.4 & 5.1 & -0.48 & $-8.49 \%$ \\
\hline 37 & -5.3 & $+/-2.8$ & -2.5 & -7.0 & 4.5 & $97.55 \%$ & -1.0 & -7.0 & -2.9 & -7.0 & 4.1 & -0.37 & $-8.26 \%$ \\
\hline 39 & -5.2 & $+/-2.8$ & -5.0 & -8.0 & 3.0 & $100.00 \%$ & -5.0 & -8.0 & -5.0 & -7.5 & 2.5 & -0.46 & $-15.21 \%$ \\
\hline 40 & \begin{tabular}{|l|}
-11.7 \\
\end{tabular} & $+/-2.8$ & -8.9 & -10.0 & 1.1 & $79.75 \%$ & -5.0 & -10.0 & -8.1 & -10.0 & 1.9 & 0.80 & $72.32 \%$ \\
\hline 41 & -6 & $+/-2.8$ & -3.2 & -6.0 & 2.8 & $98.62 \%$ & -3.0 & -6.0 & -3.5 & -6.0 & 2.5 & -0.32 & $-11.33 \%$ \\
\hline 43 & \begin{tabular}{|l|}
-4.9 \\
\end{tabular} & $+/-2.8$ & -3.5 & -6.0 & 2.5 & $100.00 \%$ & -3.5 & -6.0 & -3.7 & -6.0 & 2.3 & -0.16 & $-6.24 \%$ \\
\hline 44 & -3.9 & $+/-2.8$ & -3.0 & -6.7 & 3.7 & $97.15 \%$ & -3.0 & -8.0 & -3.0 & -6.4 & 3.4 & -0.27 & $-7.26 \%$ \\
\hline 46 & \begin{tabular}{|l|}
-7.7 \\
\end{tabular} & $+/-2.8$ & -5.0 & -6.0 & 1.0 & $100.00 \%$ & -5.0 & -6.0 & -5.1 & -6.0 & 0.9 & -0.08 & $-8.27 \%$ \\
\hline 47 & -6.3 & $+/-2.8$ & -5.0 & -9.1 & 4.1 & $97.73 \%$ & -5.0 & -10.0 & -5.0 & -8.7 & 3.7 & -0.37 & $-9.06 \%$ \\
\hline 48 & \begin{tabular}{|l|}
-11.6 \\
\end{tabular} & $+/-2.8$ & -14.0 & -14.4 & 0.4 & $47.38 \%$ & -14.0 & -10000 & -14.0 & -15.6 & 1.6 & 1.24 & $309.17 \%$ \\
\hline 49 & -16.4 & $+/-5.2$ & -11.2 & -20.0 & 8.8 & $97.52 \%$ & -5.0 & -20.0 & -11.9 & -20.0 & 8.1 & -0.70 & $-7.95 \%$ \\
\hline 51 & -4.4 & $+/-2.8$ & -1.6 & -7.0 & 5.4 & $98.42 \%$ & -1.0 & -7.0 & -2.0 & -6.8 & 4.9 & -0.55 & $-10.10 \%$ \\
\hline 52 & -4.2 & $+/-2.8$ & -3.0 & -7.0 & 4.0 & $97.57 \%$ & -3.0 & -8.0 & -3.0 & -6.7 & 3.7 & -0.35 & $-8.63 \%$ \\
\hline 53 & -5.5 & $+/-2.8$ & -2.7 & -6.0 & 3.3 & $96.54 \%$ & -1.0 & -6.0 & -2.9 & -6.0 & 3.1 & -0.16 & $-4.88 \%$ \\
\hline 55 & -5 & $+/-2.8$ & -2.2 & -7.0 & 4.8 & $97.76 \%$ & -1.0 & -7.0 & -2.6 & -7.0 & 4.4 & -0.41 & $-8.59 \%$ \\
\hline 57 & \begin{tabular}{|l|}
-14.4 \\
\end{tabular} & $+/-2.8$ & -14.0 & $\begin{array}{l}-17.2 \\
\end{array}$ & 3.2 & $96.29 \%$ & -14.0 & -20.0 & -14.0 & \begin{tabular}{|l|}
-17.1 \\
\end{tabular} & 3.1 & -0.12 & $-3.82 \%$ \\
\hline 58 & -16.9 & $+/-3.2$ & -13.7 & -20.0 & 6.3 & $97.66 \%$ & -5.0 & -20.0 & -14.0 & \begin{tabular}{|l|}
-19.8 \\
\end{tabular} & 5.8 & -0.52 & $-8.18 \%$ \\
\hline 59 & \begin{tabular}{|l|}
-4.6 \\
\end{tabular} & $+/-2.8$ & -3.0 & -7.4 & 4.4 & $98.25 \%$ & -3.0 & -8.0 & -3.0 & -6.9 & 3.9 & -0.46 & $-10.34 \%$ \\
\hline 60 & -5 & $+/-2.8$ & -5.0 & -7.8 & 2.8 & $95.45 \%$ & -5.0 & -10000 & -5.0 & -7.8 & 2.8 & 0.00 & $0.00 \%$ \\
\hline 61 & \begin{tabular}{|l|} 
\\
\end{tabular} & $+/-2.8$ & -3.0 & -6.2 & 3.2 & $96.29 \%$ & -3.0 & -13.0 & -3.0 & -6.1 & 3.1 & -0.12 & $-3.80 \%$ \\
\hline 63 & -8.4 & $+/-2.8$ & -5.6 & -7.0 & 1.4 & $85.69 \%$ & -3.0 & -7.0 & -5.0 & -7.0 & 2.0 & 0.62 & $44.35 \%$ \\
\hline 64 & \begin{tabular}{|l|}
-6.7 \\
\end{tabular} & $+/-2.8$ & -3.9 & -9.5 & 5.6 & $95.84 \%$ & -3.0 & -20.0 & -3.9 & -9.5 & 5.5 & -0.10 & $-1.75 \%$ \\
\hline 65 & -2.8 & $+/-2.8$ & -1.0 & -5.6 & 4.6 & $98.69 \%$ & -1.0 & -6.0 & -1.0 & -5.1 & 4.1 & -0.52 & $-11.28 \%$ \\
\hline 67 & \begin{tabular}{|l|}
-7.7 \\
\end{tabular} & $+/-2.8$ & -5.0 & -10.5 & 5.5 & $97.66 \%$ & -5.0 & -16.0 & -5.2 & \begin{tabular}{|l|}
-10.2 \\
\end{tabular} & 5.1 & -0.45 & $-8.14 \%$ \\
\hline 68 & -11.4 & $+/-4.5$ & -6.9 & -8.0 & 1.1 & $65.30 \%$ & -3.0 & -8.0 & -5.2 & -8.0 & 2.8 & 1.67 & $151.52 \%$ \\
\hline $69 a$ & -4.5 & $+/-2.8$ & -3.0 & -6.0 & 3.0 & $100.00 \%$ & -3.0 & -6.0 & -3.1 & -5.9 & 2.8 & -0.20 & $-6.52 \%$ \\
\hline $69 \mathrm{~b}$ & -5.2 & $+/-2.8$ & -3.0 & -7.0 & 4.0 & $100.00 \%$ & -3.0 & -7.0 & -3.4 & -7.0 & 3.6 & -0.38 & $-9.41 \%$ \\
\hline 71 & \begin{tabular}{|l|}
-18.9 \\
\end{tabular} & $+/-4.5$ & -14.4 & -20.0 & 5.6 & $96.69 \%$ & -5.0 & -20.0 & -14.7 & -20.0 & 5.3 & -0.31 & $-5.53 \%$ \\
\hline 72 & -6.7 & $+/-2.8$ & -3.9 & -6.0 & 2.1 & $92.74 \%$ & -2.0 & -6.0 & -3.6 & -6.0 & 2.4 & 0.26 & $12.39 \%$ \\
\hline
\end{tabular}

Abbreviations: $\mathrm{NM}=$ Nomogram method; $\mathrm{CM}=$ Compound method; CPD = conditional probability distribution (*) - if no

information was available regarding the lower bound (e.g. "found dead at T-2"), time zero (measurement) was taken (+) - if no information was available regarding the upper bound (e.g. "last seen alive at T-10"), T -10.000 was taken for calculation 